\title{
Electrical and dielectrical properties of tantalum oxide films grown by Nd:YAG laser assisted oxidation
}

\author{
G. Aygun ${ }^{\mathrm{a}, *}, \mathrm{R}$. Turan $^{\mathrm{b}}$ \\ a Department of Physics, İzmir Institute of Technology, Gulbahce Campus, TR-35430, Urla-İzmir, Turkey \\ b Department of Physics, Middle East Technical University, TR-06531, Ankara, Turkey
}

\section{A R T I C L E I N F O}

\section{Article history:}

Received 23 March 2007

Received in revised form 23 July 2008

Accepted 30 July 2008

Available online 3 August 2008

\section{Keywords:}

Dielectric properties

Electrical properties

Insulators

Metal Oxide Semiconductor structure

Oxidation

Tantalum oxide

Ellipsometry

Fourier Transform Infrared Spectroscopy (FTIR)

\begin{abstract}
A B S T R A C T
Tantalum pentoxide $\left(\mathrm{Ta}_{2} \mathrm{O}_{5}\right)$ thin films ( 20 to $44 \mathrm{~nm}$ ) have been grown by $1064 \mathrm{~nm}$ Nd:YAG laser oxidation of Ta deposited films with various thickness on Si. Fourier Transform Infrared (FTIR) spectrum, thickness distribution, dielectric and electrical properties of laser grown oxide layers have been studied. The effect of the sputtered Ta film thickness, laser beam energy density and the substrate temperature on the final $\mathrm{Ta}_{2} \mathrm{O}_{5}$ film structure has been determined. It is shown that the oxide layers obtained for the laser beam energy density in the range from 3.26 to $3.31 \mathrm{~J} / \mathrm{cm}^{2}$ and the substrate temperature around $350{ }^{\circ} \mathrm{C}$ have superior properties. FTIR measurement demonstrates that the $\mathrm{Ta}_{2} \mathrm{O}_{5}$ layers are obtained with the laser assisted oxidation technique. Metal Oxide Semiconductor capacitors fabricated on the grown oxide layers exhibits typical Capacitance-Voltage, Conductance-Voltage and Current-Voltage characteristics. However, the density of oxide charges is found to be slightly higher than the typical values of thermally grown oxides. The conduction mechanism studied by Current-Voltage measurements of the capacitors indicated that the current flow through the oxide layer is modified Poole-Frenkel type. It is concluded that the $\mathrm{Ta}_{2} \mathrm{O}_{5} \mathrm{films}$ formed by the technique of Nd:YAG laser-enhanced oxidation at relatively low substrate temperatures are potentially useful for device applications and their properties can be further improved by post oxidation annealing processes.
\end{abstract}

(C) 2008 Elsevier B.V. All rights reserved.

\section{Introduction}

To overcome the scaling limit of microelectronic device dimensions, Si-based dielectric materials need to be replaced by advanced high permittivity (high- $\kappa$ ) materials. Therefore, there has been a great demand lately for alternative gate dielectrics [1-3]. Among the high- $\kappa$ materials like $\mathrm{ZrO}_{2}, \mathrm{HfO}_{2}, \mathrm{Ta}_{2} \mathrm{O}_{5}, \mathrm{Y}_{2} \mathrm{O}_{3}, \mathrm{TiO}_{2}$ metal oxides, $\mathrm{Ta}_{2} \mathrm{O}_{5}$ is one of the most promising candidates to replace $\mathrm{SiO}_{2}$ as a memory dielectric in storage capacitors, since it has excellent step coverage characteristics, high dielectric constant greater than 20 (depending on the conditions during growth), high breakdown field, relatively low leakage currents resulting in a high storage charges and chemically stable structure [2-7].

There are a number of ways to fabricate $\mathrm{Ta}_{2} \mathrm{O}_{5}$ such as chemical vapor deposition techniques, sputtering, evaporation, sol-gel methods, atomic layer deposition, ion-assisted deposition, laser oxidation of Ta layer [6,7]. Fabrication method strongly affects the structural and electrical properties of grown $\mathrm{Ta}_{2} \mathrm{O}_{5}$ layers [7]. However, the best production method in terms of storage capacitor applications is not yet clear.

\footnotetext{
* Corresponding author. Tel.: +90 23275077 15; fax: +90 2327507707. E-mail addresses: aygun@photon.iyte.edu.tr, gulnuraygun@iyte.edu.tr (G. Aygun).
}

Being a local and low temperature process, laser assisted oxidation is a challenging, but promising approach for the production of future devices and, therefore, it can be used as an alternative technique to produce high- $\kappa$ oxides $[8,9]$. The oxide layer fabricated in this way needs to be studied in terms of mainly electrical properties that are essential for Dynamical Random Access Memory applications. In this work, various aspects of $\mathrm{Ta}_{2} \mathrm{O}_{5}$ films fabricated by Pulsed Laser Oxidation of radio frequency (rf) sputtered Ta layer, i.e. formation of $\mathrm{Ta}_{2} \mathrm{O}_{5}$ by laser assisted oxidation, thickness profile of the grown films, and their dielectric and electrical properties with the analysis of leakage current mechanisms have been studied.

\section{Experimental procedure}

Tantalum films with a thickness of 10,15 and $20 \mathrm{~nm}$ were deposited on Si wafers by rf sputtering of tantalum target $(99.99 \%$ purity) in an Ar atmosphere. The working gas pressure, rf power density and deposition rate were $3 \mathrm{~Pa}, 2.2 \mathrm{~W} / \mathrm{cm}^{2}, 9.3 \mathrm{~nm} / \mathrm{min}$, respectively. The substrate was not heated intentionally during the tantalum deposition and presumably remained close to room temperature. Subsequently, the samples were laser oxidized in vacuum chamber. During laser oxidation, the substrate temperature was varied between 250 and $400{ }^{\circ} \mathrm{C}$, the laser beam energy density (laser power) was in the range from 3.21 to $3.36 \mathrm{~J} / \mathrm{cm}^{2}$ per pulse, and 
the oxygen gas pressure was $123 \mathrm{~Pa}$. The laser beam is scanned on the surface of the sample by means of a computer controlled X-Y scanner system which has a $3 \mathrm{~cm}$ converging lens with a focal length of approximately $25 \mathrm{~cm}$ generated a $1.8 \mathrm{~mm}$ diameter of spot size on the substrate. By means of this X-Y scanner system, the laser light shines on a region on the substrate approximately $4 \times 4 \mathrm{~mm}^{2}$ and this area can be reduced or increased by software. The details of the laser oxidation system and process parameters can be found elsewhere $[8,9]$.

Following the oxidation process of Ta films, the oxide thickness, $d$, and the refractive index, $n$, of the oxide layers were determined by single wavelength ellipsometer working at $632.8 \mathrm{~nm}$ (Rudolph Auto EL II). A Fourier Transform Infrared (FTIR) Spectroscopy (Bruker Equinox 55) was used to determine the chemical composition and structure of the films at the substrate temperature of $350{ }^{\circ} \mathrm{C}$ and laser power of $3.3 \mathrm{~J} / \mathrm{cm}^{2}$ pulse.

The electrical characterization of the layers was carried out using Metal Oxide Semiconductor (MOS) capacitors with evaporated Al gate electrodes with an area of $1.96 \times 10^{-3} \mathrm{~cm}^{2}$. The back side of the wafers was hydrofluoric acid cleaned and covered by Al to form ohmic contact. The dielectric and electrical characteristics of the layers were obtained from the Capacitance-Voltage $(C-V)$, Conductance-Voltage $(G-V)$, and Current-Voltage $(I-V)$ measurements. High frequency regime $(1 \mathrm{k}, 10 \mathrm{k}, 100 \mathrm{k}, 1 \mathrm{MHz}$ ) was used for the $C-V$ and $G-V$ measurements and series resistance correction was performed for $100 \mathrm{kHz}$ and $1 \mathrm{MHz} C-V$ and $G-V$ data. Effective dielectric constant $\left(\varepsilon_{\text {eff }}\right)$, flatband voltage $\left(V_{\mathrm{FB}}\right)$, different types of oxide charges/charge densities, i.e. $Q_{\mathrm{f}}$ (fixed oxide charges), $Q_{\mathrm{sl}}$ (slow states), $D_{\text {it }}$ (fast states) and hysteresis effect were extracted from the $C-V$ and $G-V$ data. Using the $I-V$ measurements of the oxide layers, the conduction mechanisms in $\mathrm{Ta}_{2} \mathrm{O}_{5}$ oxide layer were determined.

\section{Results and discussions}

\subsection{Formation of $\mathrm{Ta}_{2} \mathrm{O}_{5}$ film}

Fig. 1 shows the FTIR spectra of laser oxidized layer produced from initial $10 \mathrm{~nm}$ thick Ta film on Si. The spectra correspond to the film obtained at laser beam energy density of $3.3 \mathrm{~J} / \mathrm{cm}^{2}$, the substrate temperature of $350{ }^{\circ} \mathrm{C}$, and the oxide layer thickness of $20 \mathrm{~nm}$. Although the spectra were taken between 400 and $4000 \mathrm{~cm}^{-1}$, the region of $400-1200 \mathrm{~cm}^{-1}$ is displayed in the figures only because of the importance of the low wavenumber region $\left(<1100 \mathrm{~cm}^{-1}\right)$ in the detection of the tantalum oxide-related bonds. As evidenced by the weakness of the $\mathrm{OH}$ signal around $3300-3400 \mathrm{~cm}^{-1}$ of the FTIR spectra, the films are almost moisture-free.

A dominant absorption feature around $650 \mathrm{~cm}^{-1}$ and a wide shoulder like absorption band with a small intensity between 450 and $550 \mathrm{~cm}^{-1}$ indicate the presence of tantalum oxide(s) in the layers $[10,11]$. A wide shoulder like absorption peak with a small intensity dip

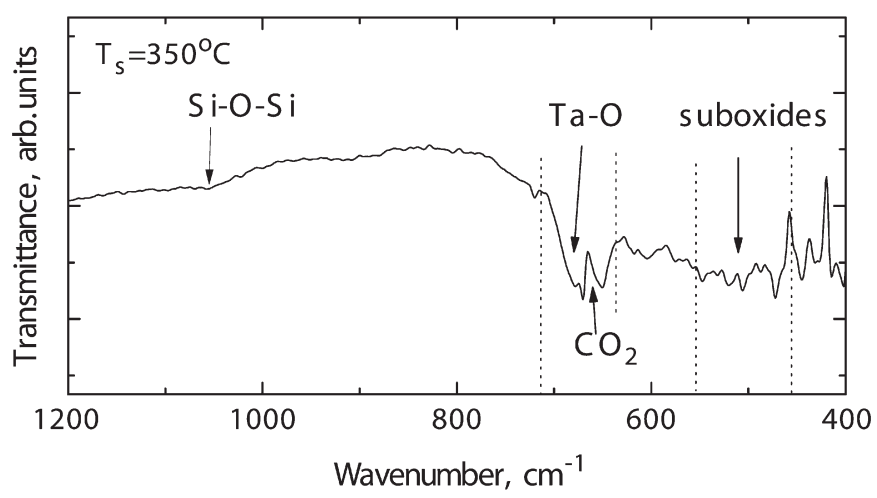

Fig. 1. FTIR spectra of the $20 \mathrm{~nm}$ thick oxide grown at the substrate temperature of $350{ }^{\circ} \mathrm{C}$ and the laser beam energy density of $3.3 \mathrm{~J} / \mathrm{cm}^{2}$.

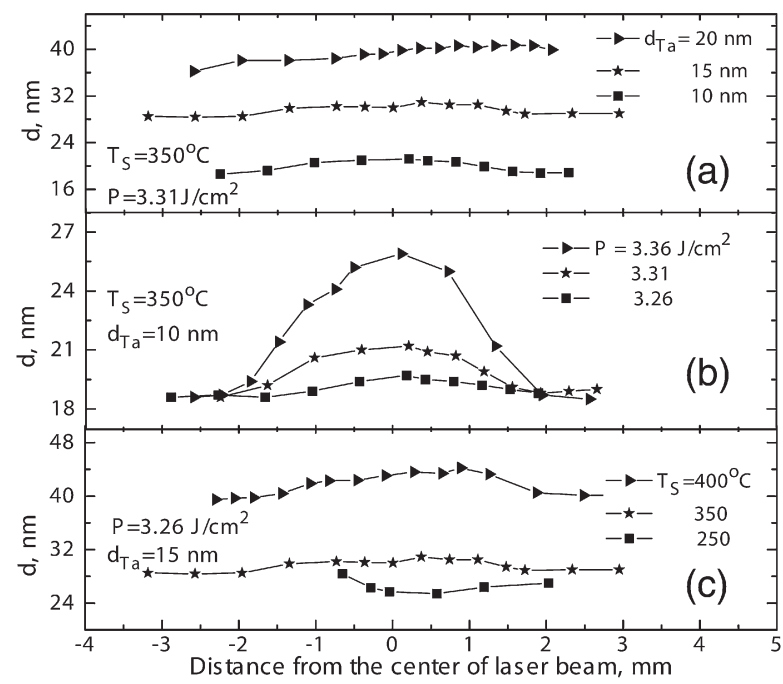

Fig. 2. Oxide thickness distribution profile with respect to the center of the laser beam for the conditions of (a) thickness of rf-sputtered Ta film (b) laser beam energy density (c) substrate temperature.

between 850 and $1000 \mathrm{~cm}^{-1}$ is attributed to the presence of very tiny amount of suboxides in the oxidized layer [11]. The feature superimposed on the main broad signal at $670 \mathrm{~cm}^{-1}$ is associated with vibration modes of $\mathrm{CO}_{2}$ resulting probably from the air ambient during the measurements. Since this peak is not related to the oxidation process, we will not discuss it further.

One of the typical features of the high- $\kappa$ dielectrics grown on $\mathrm{Si}$ substrate is that an ultra thin $\mathrm{SiO}_{2}$ formed at the interface $[2,4,5,7]$. Although $\mathrm{Ta}_{2} \mathrm{O}_{5}$ is not an exception, measured spectra did not reveal a strong indication for the presence of $\mathrm{Si}-\mathrm{O}$ stretching band which is typically around $1070-1100 \mathrm{~cm}^{-1}$. The film has very small bands in this region which can be attributed to the presence of $\mathrm{Si}-\mathrm{O}-\mathrm{Si}$ stretching vibration mode [12]. Based on this observation, one can conclude that interfacial layer containing $\mathrm{SiO}_{2}$ and/or intermediate oxidation states of $\mathrm{Si}$, is extremely thin if present for this specific film.

\subsection{Thickness distribution}

This section presents the discussions on the variation of the $\mathrm{Ta}_{2} \mathrm{O}_{5}$ film thickness with respect to the distance from the center of the laser beam as a function of process parameters like thickness of the sputtered Ta film, laser beam energy density and substrate temperature. Fig. 2(a) represents the effect of Ta film thickness for 10,15 and $20 \mathrm{~nm}$ initial thick rf-sputtered Ta films. The laser beam energy density and the substrate temperature are $3.31 \mathrm{~J} / \mathrm{cm}^{2}$ and $350{ }^{\circ} \mathrm{C}$. The refractive index values of oxides are 1.9, 2.1 and 2.1 for 10,15 and $20 \mathrm{~nm}$ initial thick Ta films respectively and their values are very close to those of bulk $\mathrm{Ta}_{2} \mathrm{O}_{5}$ (2.1) [3]. The oxide thicknesses being $\sim 22.5 \mathrm{~nm}$, $\sim 32.5 \mathrm{~nm}$ and $41.5 \mathrm{~nm}$ for initial 10,15 and $20 \mathrm{~nm}$ thick Ta films are in agreement with the expectation of approximately twice that of initial Ta film thickness. It is also seen that the highest value of the oxide thickness, $d$, is measured at the center of the laser beam (denoted by " 0 " in Fig. 2) and the thickness distribution is approximately uniform across the laser irradiated region. The thickness variation across the oxidized region is more homogenous for initially thicker Ta films and a relatively flat region can be found over the distance of $2 \mathrm{~mm}$ at the center of the laser beam, across which the thickness variation is within $\sim 8 \%$ for initially $10 \mathrm{~nm}$ thick Ta films and $2.2 \mathrm{~nm}$ flat region is obtained for the oxides of higher initial thick Ta films.

The impact of laser beam energy density on oxide thickness, $d$, is shown in Fig. 2(b). The substrate temperature and the initial Ta film thickness were $350{ }^{\circ} \mathrm{C}$ and $10 \mathrm{~nm}$ during the oxidation, respectively. The refractive index values are $1.9,1.9$ and 2.2 corresponding to laser 

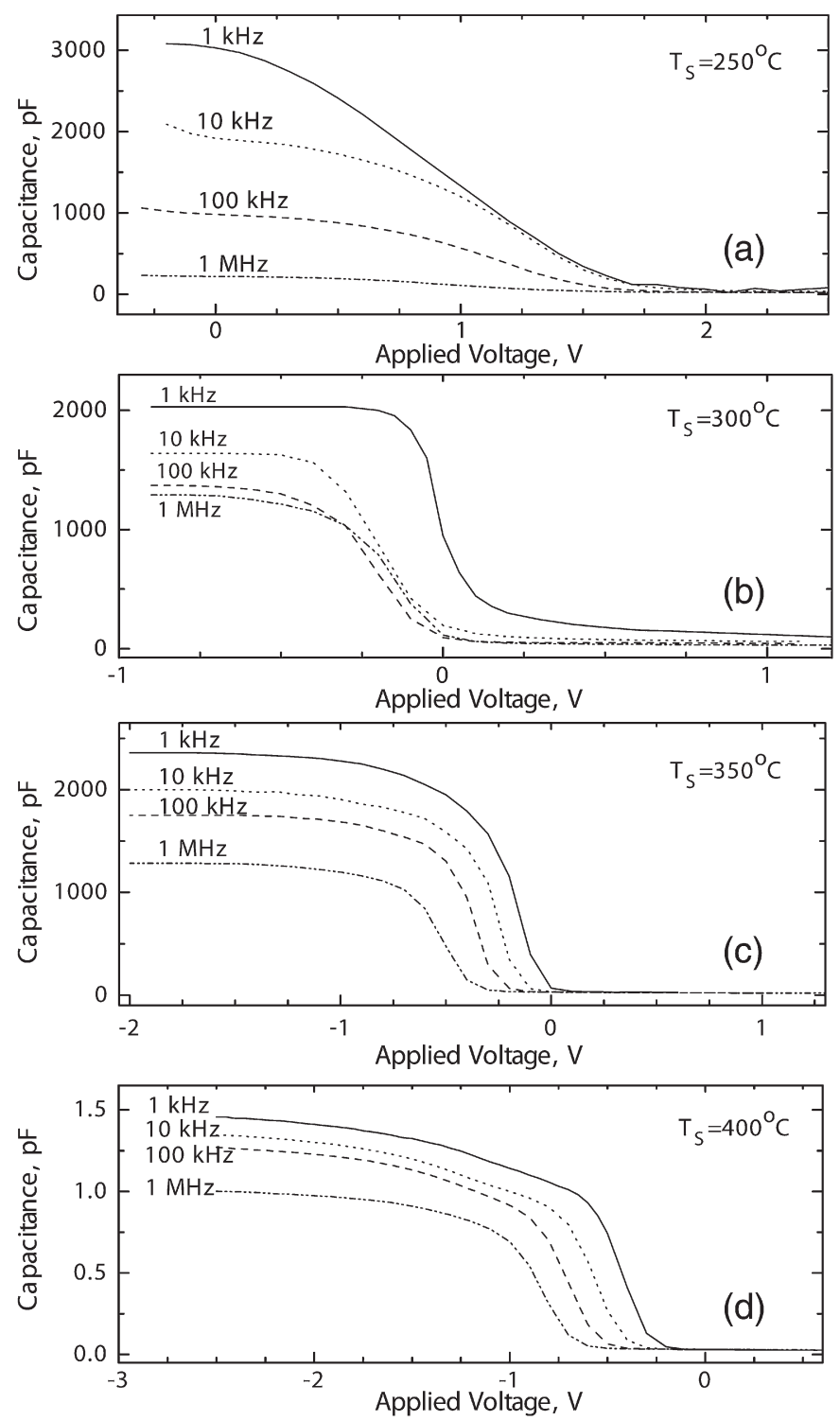

Fig. 3. $C-V$ curves measured at different frequencies $(1,10,100,1000 \mathrm{kHz})$ for $21 \mathrm{~nm}$ thick film produced at (a) $250{ }^{\circ} \mathrm{C}$ (b) $300{ }^{\circ} \mathrm{C}$ (c) $350{ }^{\circ} \mathrm{C}$ (d) $400{ }^{\circ} \mathrm{C}$.

power of 3.26, 3.31 and $3.36 \mathrm{~J} / \mathrm{cm}^{2}$. The refractive index being 2.2 for $3.36 \mathrm{~J} / \mathrm{cm}^{2}$ is close to that of bulk $\mathrm{Ta}_{2} \mathrm{O}_{5}$. The lateral variations of oxide thicknesses are all Gaussian-like and their values at the center are close to each other for the lower two laser powers, namely $\sim 19.5 \mathrm{~nm}$ for $3.26 \mathrm{~J} / \mathrm{cm}^{2}$ and $21 \mathrm{~nm}$ for $3.31 \mathrm{~J} / \mathrm{cm}^{2}$, but it increases up to $26 \mathrm{~nm}$ for the laser power of $3.36 \mathrm{~J} / \mathrm{cm}^{2}$ having a relatively narrow Gaussian thickness profile. The thickness variation is obtained around $1.4 \%$ for $P=3.26$ and $3.31 \mathrm{~J} / \mathrm{cm}^{2}$ while it increases little bit more to $\sim 1.7 \%$ for $P=3.36 \mathrm{~J} / \mathrm{cm}^{2}$ over the distance of $1 \mathrm{~mm}$ from the laser beam center. These results show that the expected oxide thickness, approximately twice that of initial Ta film, is obtained at relatively lower laser powers, i.e. $3.26-3.31 \mathrm{~J} / \mathrm{cm}^{2}$, while it increases up to $\sim 2.5$ times that of initial thick Ta film for the laser power of $3.36 \mathrm{~J} / \mathrm{cm}^{2}$. This could be due to the fact that a $\mathrm{SiO}_{2}$ layer is formed at the interface between $\mathrm{Ta}_{2} \mathrm{O}_{5}$ and $\mathrm{Si}$ substrate as a result of higher laser power. Presence of $\mathrm{SiO}_{2}$ layer at the interface is undesirable because of its effect on the effective dielectric constant of the oxide layer. On the other hand, Ta may not be totally oxidized for lower laser energy fluences [9]. An optimum interval for the laser power should exist for uniform oxidation. In the present case, most uniform oxide layers were obtained at the laser power ranging from 3.26 to $3.31 \mathrm{~J} / \mathrm{cm}^{2}$ per pulse.
The effect of the substrate temperature on the thickness distribution of the $\mathrm{Ta}_{2} \mathrm{O}_{5}$ layers is given in Fig. 2(c). The thickness of the initial Ta film and the laser power were $15 \mathrm{~nm}$ and $3.26 \mathrm{~J} / \mathrm{cm}^{2}$, respectively. It is obvious that all curves have a Gaussian shape and the thickness variation over $1 \mathrm{~mm}$ at the center of the oxidized region changes between $0.5 \%$ and $0.7 \%$ which is very low. The maximum oxide thickness measured at the center of the laser oxidized region is around $25.5 \mathrm{~nm}$ for $250{ }^{\circ} \mathrm{C}, 31 \mathrm{~nm}$ for $350{ }^{\circ} \mathrm{C}$ and $44 \mathrm{~nm}$ for $400{ }^{\circ} \mathrm{C}$. The ideal thick oxide for $15 \mathrm{~nm}$ thick Ta film is obtained around $350{ }^{\circ} \mathrm{C}$. However, for $T_{\mathrm{S}}=250{ }^{\circ} \mathrm{C}$, the oxide thickness (lower than expected value) has an opposite shape of Gaussian thickness distribution, namely the lowest thickness at the center and then sudden increase at the periphery, which indicates that the layer is mostly metallic in the periphery while a slightly oxidized region is at the center. The refractive index values were measured to be 2.1 and 2.0 respectively for $350{ }^{\circ} \mathrm{C}$ and $400{ }^{\circ} \mathrm{C}$. Since the oxide layer thickness for $400{ }^{\circ} \mathrm{C}$ increases suddenly to about $44 \mathrm{~nm}$ while the expected value is $30 \mathrm{~nm}$, and the refractive index value is lower than that of $350{ }^{\circ} \mathrm{C}$, it can be concluded that the Si substrate at the interface is also oxidized containing the suboxide forms of $\mathrm{Si}$, Ta and $\mathrm{O}$ in addition to the oxidation of the Ta film.

Oxide growth conditions affect the crystallinity of the grown films. This situation was examined for various growth conditions of Nd:YAG laser oxidized tantalum films in our earlier publication. X-ray diffraction data showed that the films grown at or below $350{ }^{\circ} \mathrm{C}$ are amorphous while the films grown at higher temperature are polycrystalline with orthorhombic structure [9].

\subsection{Dielectric and electrical parameters}

In this section, the electrical properties, i.e. $C-V, G-V$ and $I-V$ of 4 samples produced at $T_{\mathrm{S}}=250,300,350,400{ }^{\circ} \mathrm{C}$ are presented. $\mathrm{C}-\mathrm{V}$ curves were taken at high frequencies namely $1 \mathrm{kHz}, 10 \mathrm{kHz}, 100 \mathrm{kHz}$, $1 \mathrm{MHz}$ for MOS capacitors with $1.96 \times 10^{-3} \mathrm{~cm}^{2} \mathrm{Al}$ gate area. Series resistance corrections were applied to $100 \mathrm{kHz}$ and $1 \mathrm{MHz} C-V$ and $G-V$ data. High frequency $C-V$ and $G-V$ data have been analyzed to obtain $\varepsilon_{\mathrm{eff}}, V_{\mathrm{FB}}, Q_{\mathrm{f}}, Q_{\mathrm{s}}$, and $D_{\mathrm{it}}$. Fig. 3(a-d) shows $C-V$ curves with accumulation, depletion and inversion regions after the series resistance correction has been applied. However, the frequency dispersion seen in the accumulation part of the $C-V$ curves indicates that the series resistance effect cannot be eliminated totally. This effect is more visible in the high frequency regimes as expected [13].

The $\varepsilon_{\text {eff }}$ of the oxide layers ( $21 \mathrm{~nm}$ thick) was determined from the capacitance value at accumulation mode of $1 \mathrm{MHz}, 100 \mathrm{kHz}, 10 \mathrm{kHz}$ and $1 \mathrm{kHz} C-V$ curves of the MOS structure. The $\varepsilon_{\text {eff }}$ values corresponding to each high frequency $C-V$ curve are given in Table 1 for all samples at the given substrate temperatures, and seen that almost

Table 1

Dielectric and electrical properties obtained from capacitance and conductance with respect to voltage graphs

\begin{tabular}{|c|c|c|c|c|c|}
\hline \multirow[t]{2}{*}{$f, \mathrm{kHz}$} & & \multicolumn{4}{|l|}{$T_{\mathrm{s}},{ }^{\circ} \mathrm{C}$} \\
\hline & & 250 & 300 & 350 & 400 \\
\hline \multirow[t]{4}{*}{$\varepsilon_{\text {eff }}$} & 1 & 37.13 & 23.22 & 28.50 & 17.64 \\
\hline & 10 & 22.61 & 19.78 & 23.90 & 15.99 \\
\hline & 100 & 11.77 & 14.42 & 17.00 & 15.42 \\
\hline & 1000 & 2.81 & 15.33 & 15.10 & 12.16 \\
\hline \multirow[t]{4}{*}{$V_{\mathrm{FB}}, \mathrm{V}$} & 1 & 1.34 & 0.056 & -0.014 & -0.32 \\
\hline & 10 & 1.36 & -0.040 & -0.084 & -0.46 \\
\hline & 100 & 1.28 & -0.172 & -0.203 & -0.59 \\
\hline & 1000 & 1.08 & -0.017 & -0.371 & -0.71 \\
\hline \multirow[t]{4}{*}{$Q_{\mathrm{f}} 10^{12} \mathrm{~cm}^{-2}$} & 1 & -19.96 & -4.625 & -5.171 & -1.767 \\
\hline & 10 & -12.31 & -3.442 & -3.947 & -1.059 \\
\hline & 100 & -6.15 & -2.007 & -2.789 & -0.444 \\
\hline & 1000 & -0.79 & -2.763 & -1.345 & 0.037 \\
\hline$D_{\text {it }} 10^{12} \mathrm{~cm}^{-2} \mathrm{eV}^{-1}$ & 1000 & 1.6 & 1.5 & 2.1 & 2.4 \\
\hline$Q_{\mathrm{sl}} 10^{11} \mathrm{~cm}^{-2}$ & 1000 & -1.48 & 2.07 & 4.18 & 3.846 \\
\hline
\end{tabular}


all $\varepsilon_{\text {eff }}$ values are higher than that of ideal $\mathrm{SiO}_{2}\left(\varepsilon_{\mathrm{SiO}_{2}}=3.9\right)$. Since accumulation capacitance $\left(C_{\text {acc }}\right)$ values depend on the frequency (Fig. 3a-d), so do $\varepsilon_{\text {eff }}$ values. The $\varepsilon_{\text {eff }}$ values of grown oxide films change between 12 and 15 at $1 \mathrm{MHz}$ frequency limit except that for $T_{\mathrm{s}}=250{ }^{\circ} \mathrm{C}$ oxide. The $\varepsilon_{\text {eff }}$ values determined from these measurements are comparable to the values of oxides grown by other techniques $[4,7]$. For lower frequencies, the corresponding $\varepsilon_{\text {eff }}$ values increase as a result of the increment in the accumulation capacitance values as frequency decreases.

Our recent results [9] support that the effective oxidation temperature for Ta films starts somewhere in between $300{ }^{\circ} \mathrm{C}$ and $350{ }^{\circ} \mathrm{C}$. For the lowest $T_{\mathrm{s}}, 250{ }^{\circ} \mathrm{C}$, the $\varepsilon_{\text {eff }}$ is too much variable with respect to frequency showing that the grown layer is not uniform. The calculated $\varepsilon_{\text {eff }}$ data for $300{ }^{\circ} \mathrm{C}$ and $350{ }^{\circ} \mathrm{C}$ are reliable, and $\varepsilon_{\text {eff }}$ values are comparable to the results of other groups using different growth techniques [4,7]. However, the decrease in $\varepsilon_{\text {eff }}$ values when $T_{\mathrm{s}}$ increases to $400{ }^{\circ} \mathrm{C}$ is an evidence that a $\mathrm{SiO}_{2}$ layer is formed at the interface [9] resulting in a smaller $\varepsilon_{\text {eff }}$ value when the substrate temperature exceeds a certain value.

The $Q_{\mathrm{f}}$ values are calculated from the shift in $V_{\mathrm{FB}}$ which is obtained from the position at the conduction peak together with work function difference between $\mathrm{Al}$ gate and $\mathrm{Si}(-0.7 \mathrm{eV})$ (Table 1$)$. The $Q_{\mathrm{f}}$ at $1 \mathrm{MHz}$ frequency is found to be $\sim 0.4 \times 10^{11} \mathrm{~cm}^{-2}$ for $T_{\mathrm{s}}=400{ }^{\circ} \mathrm{C}$, whereas it changes from $\sim\left(-7.9 \times 10^{11} \mathrm{~cm}^{-2}\right)$ to $\sim\left(-27.6 \times 10^{11} \mathrm{~cm}^{-2}\right)$ for $T_{\mathrm{s}}=250$ $350{ }^{\circ} \mathrm{C}$ oxides. The $Q_{\mathrm{f}}$ values calculated for laser grown oxides are approximately one order higher than those of common production methods of $\mathrm{Ta}_{2} \mathrm{O}_{5}$ films [4] and this behavior of $Q_{\mathrm{f}}$ is generally associated with structural imperfections, bond defects and poor oxidation process. In addition, the fixed oxide charges often originate from the incomplete chemical bonding of the atoms near the dielectric/semiconductor interface [6]. One particular example for these electrically active defects in $\mathrm{Ta}_{2} \mathrm{O}_{5}$ is the oxygen vacancies [4].

Laser grown oxides exhibit hysteresis at $1 \mathrm{MHz} C-V$ curves when the gate voltage is swept from accumulation to inversion and then from inversion to accumulation. This indicates the presence of slow states, $Q_{s l}$, which are located very close to the Si/oxide interface (Table 1). The shift in the $C-V$ curves at the flat band voltage value, $\Delta V_{\text {hyst }}$, at $1 \mathrm{MHz} C-V$ curve changes between $-51 \mathrm{mV}$ and $-120 \mathrm{mV}$ giving rise to $2.1-4.2 \times 10^{11} \mathrm{~cm}^{-2}$ slow states for the substrate temperatures, $T_{\mathrm{s}}=300-400{ }^{\circ} \mathrm{C}$. For the lowest substrate temperature, i.e. $T_{\mathrm{S}}=250{ }^{\circ} \mathrm{C}, Q_{\mathrm{sl}}$ is obtained as $-1.5 \times 10^{11} \mathrm{~cm}^{-2}\left(\Delta V_{\mathrm{FB}}^{\text {hyst }}=0.200 \mathrm{~V}\right)$. These values are comparable to those obtained by other groups [4].

The $D_{\text {it }}$ values were calculated using Terman method [13,14]. At high frequencies $(\omega \tau \gg 1)$, interface traps cannot follow the ac voltage swing, which yields the high frequency curve, free of capacitance due to interface traps. As a result, $C-V$ curve at high frequencies has a stretch out with respect to low frequency regime due to interface trap charges. Terman method uses the distortion of high frequency $C-V$ curves caused by the existence of interface charges to calculate $D_{\text {it }}$ value using;

$D_{\mathrm{it}}\left(\Psi_{\mathrm{S}}\right)=\frac{C_{\mathrm{it}}\left(\Psi_{\mathrm{S}}\right)}{q}=\frac{1}{q}\left[C_{\mathrm{ox}}\left(\left(\frac{d \Psi_{S}}{d V_{G}}\right)^{-1}-1\right)-C_{\mathrm{S}}\right]$

where $C_{\mathrm{S}}$ is the surface capacitance of silicon, $\psi_{\mathrm{S}}$ is the surface band bending of silicon, and $q$ is the elementary charge. By comparing the experimental and theoretical $\left(\mathrm{d} \psi_{\mathrm{S}} / \mathrm{d} V_{\mathrm{G}}\right)$, one can obtain the $D_{\mathrm{it}}$ of the $C-V$ curves [13].

The values of $D_{\text {it }}$ as found from $1 \mathrm{MHz} C-V$ curves are obtained in the range between $1.5 \times 10^{12}$ and $2.4 \times 10^{12} \mathrm{~cm}^{-2} \mathrm{eV}^{-1}$ (Table 1 ). These values are comparable to the values obtained from the other oxide growth methods $[4,14]$.

\subsection{I-V characteristics of the capacitors}

Fig. 4 shows the leakage current density, J, measured through the $\mathrm{Al}-\mathrm{Ta}_{2} \mathrm{O}_{5}-\mathrm{Si}$ capacitors as a function of applied voltage for substrate

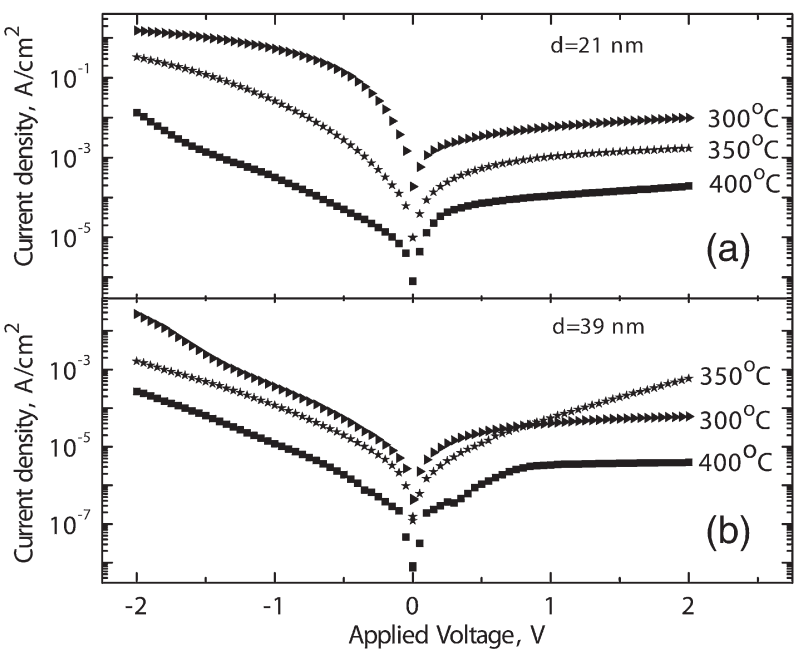

Fig. 4. The leakage current density versus applied voltage for $T_{\mathrm{s}}=300{ }^{\circ} \mathrm{C}, 350{ }^{\circ} \mathrm{C}, 400{ }^{\circ} \mathrm{C}$ (a) $d_{\text {oxide }}=21 \mathrm{~nm}$ (b) $d_{\text {oxide }}=39 \mathrm{~nm}$.

temperatures, $T_{\mathrm{s}}$, of $300,350,400{ }^{\circ} \mathrm{C}$. The effective oxide thickness values measured by the ellipsometry are given as (a) $21 \mathrm{~nm}$ and (b) $39 \mathrm{~nm}$. Since the oxide quality for the substrate temperature of $250{ }^{\circ} \mathrm{C}$ and lower $T_{\mathrm{s}}$ levels is not enough, $I-V$ characteristics were not examined for this sample. It is apparent from the comparison of Fig. 4 (a) and (b) that the leakage current density decreases by two orders of magnitude with increasing oxide thickness indicating that electrically and stoichiometrically better oxide layers are obtained for the thicker films formed at higher substrate temperatures. The leakage current density for $39 \mathrm{~nm}$ oxide is very low being in the range of $10^{-9} \mathrm{~A} / \mathrm{cm}^{2}$, however, it is around $10^{-7} \mathrm{~A} / \mathrm{cm}^{2}$ for $21 \mathrm{~nm}$ thick oxide.

The variations of the current density in the forward bias conditions (negative applied voltage values for which electrons are injected from the $\mathrm{Al}$ gate for p-type $\mathrm{Si}$ ) is small for $300{ }^{\circ} \mathrm{C}$ to $350{ }^{\circ} \mathrm{C}$ while there is a sharp decrease from $350^{\circ} \mathrm{C}$ to $400{ }^{\circ} \mathrm{C}$, indicating formation of a better insulation in the samples oxidized at higher temperatures. Although the leakage current density decreases with increasing $T_{\mathrm{s}}$ in most cases, it shows an abnormal increase in the reverse bias part of the $I-V$ curve of the sample formed at $350{ }^{\circ} \mathrm{C}$ (Fig. 4(b)). This could result either from the pin-holes present in the grown oxide or from the undesired contact of the MOS electrode to the regions where the grown oxide has poor quality.

Lower $\varepsilon_{\text {eff }}$ value for the films grown at higher temperatures $\left(400{ }^{\circ} \mathrm{C}\right.$ ) indicates the presence of a $\mathrm{SiO}_{2}$ interfacial layer between $\mathrm{Si}$ substrate and $\mathrm{Ta}_{2} \mathrm{O}_{5}$. This layer might play an important role in the variation of the current density. When a sufficiently thick interfacial $\mathrm{SiO}_{2}$ is formed, it may dominate the current flow through the oxide [7]. The decrease in $J$ with increasing $T_{\mathrm{S}}$ can then be explained with the less amounts of defects (such as dangling bonds or lack of oxygen) in the oxide structure of the films and formation of $\mathrm{SiO}_{2}$ interfacial layer which provides better barrier for electrical conduction.

\subsection{Conduction mechanisms}

The current flow through the $\mathrm{Ta}_{2} \mathrm{O}_{5}$ films can be described by using various conduction mechanisms whose importance vary with the electric field. These are (i) electronic hoping conduction, (ii) field assisted emission, (iii) Poole-Frenkel (PF) effect, (iv) double barrier tunneling, (v) direct tunneling, (vi) Fowler-Nordheim tunneling (vii) Schottky emission (SE) [15]. One or more of these mechanisms can be applied depending on various device and measurement parameters $[2,15,16]$. The conduction in thin $\mathrm{Ta}_{2} \mathrm{O}_{5}$ films has been generally interpreted by two d.c. conduction mechanisms, i.e. SE which is electrode limited or PF which is bulk limited mechanisms 
[17]. It was reported that the conduction mechanism is strictly bulk limited for thermally oxidized $\mathrm{Ta}_{2} \mathrm{O}_{5}$ films, while it is, electrode limited especially at low voltages for highly imperfect films having large numbers of oxygen deficiencies [18,19].

Because of the non-uniformity in the oxides grown by laser oxidation, the major dominating current type is hard to determine. However, the analysis have strongly indicated that the conduction mechanism through the laser grown $\mathrm{Ta}_{2} \mathrm{O}_{5}$ films in the applied voltage ranges is governed by the PF in the samples having a barrier height separating the traps from the conduction band. PF is based on the emission of trapped electrons toward the conduction band of the insulator $[20,21]$. Current density governed by the PF mechanism through the dielectric is given as [22];

$J_{\mathrm{PF}}=\operatorname{CEexp}\left[\frac{q}{k_{\mathrm{B}} T}\left(-\Phi_{0}+\frac{1}{r}\left(\frac{q E}{\pi \varepsilon_{0} K_{\mathrm{r}}}\right)^{1 / 2}\right)\right]$

where $J_{\mathrm{PF}}$ is the current density, $C$ is the temperature dependent constant related to the density of trapping centers, $E$ is the electric field in $\mathrm{Ta}_{2} \mathrm{O}_{5}, q$ is the electronic charge, $\Phi_{0}$ is the barrier height separating the traps from the conduction band, $k_{\mathrm{B}}$ is the Boltzmann constant, $T$ is the absolute temperature, $\varepsilon_{0}$ is the permittivity of free space, and $K_{r}$ is the high frequency dynamic dielectric constant, that is equal to the square of the refractive index. $r$ is a degree of compensation whose value changes between 1 and $2(1 \leq r \leq 2)[20,21]$, and it defines the effect of trapping or acceptor sensors. When $r$ is equal to 1 , then it is named as normal PF, while it corresponds to modified Poole-Frenkel effect or Poole-Frenkel with compensation when $r=2$. If the plot of $\ln (J / E)$ versus $E^{1 / 2}$ results in a straight line, it suggests that the conduction is dominated by PF mechanism and $r \sqrt{K_{r}}$ value can be extracted from the measured curve. Since $r$ changes between 1 and 2 , and $K_{r}$ is the square of refractive index value, then the range for $r \sqrt{K_{r}}$ can be counted as normal when its value is between 1.9 and 4.5.

Fig. 5 shows $\ln (J / E)$ versus $E^{1 / 2}$ plot with fitting lines Eq. (2) of laser oxidized $\mathrm{Ta}_{2} \mathrm{O}_{5}$ layers for 300,350 and $400{ }^{\circ} \mathrm{C}$ for (a) $21 \mathrm{~nm}$, and (b) $39 \mathrm{~nm}$ oxide. The calculated $r \sqrt{K_{r}}$ values at the given substrate temperatures from the fitted lines is shown in Table 2. It is known that formation of a very thin layer of suboxides containing $\mathrm{Si}$, Ta and $\mathrm{O}$ is inevitable in most cases $[4,7]$. Based on the spectroscopic reflectance

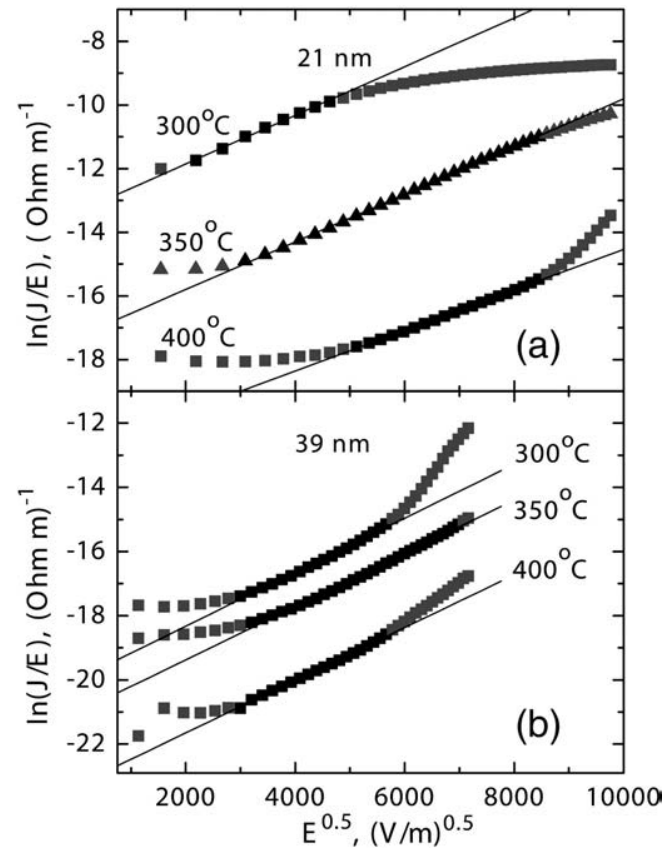

Fig. 5. In $(J / E)$ versus $\sqrt{E}$ for laser oxidized $\mathrm{Ta}_{2} \mathrm{O}_{5}$ layers grown at $T_{\mathrm{s}}=300{ }^{\circ} \mathrm{C}, 350{ }^{\circ} \mathrm{C}$, $400{ }^{\circ} \mathrm{C}$ for the oxide thicknesses of; (a) $d_{\text {oxide }}=21 \mathrm{~nm}$ (b) $d_{\text {oxide }}=39 \mathrm{~nm}$.
Table 2

Poole-Frenkel conduction mechanism constants, $r \sqrt{K_{r}}$, for 21 and $39 \mathrm{~nm}$ oxides with respect to substrate temperature

\begin{tabular}{llll}
\hline & $r \sqrt{K_{r}}$ & & \\
\cline { 2 - 4 } & $300{ }^{\circ} \mathrm{C}$ & $350{ }^{\circ} \mathrm{C}$ & $400{ }^{\circ} \mathrm{C}$ \\
\hline $21 \mathrm{~nm}$ oxide & 3.83 & 3.91 & 4.60 \\
$39 \mathrm{~nm}$ oxide & 3.48 & 3.53 & 3.57 \\
\hline
\end{tabular}

measurements [23] and XPS (X-ray Photoelectron Spectroscopy) depth profiling results of laser oxidized $\mathrm{SiO}_{2}$ layers [24], it is again expected that the laser oxidized $\mathrm{Ta}_{2} \mathrm{O}_{5}$ layers could have suboxide layer at the interface. Since the refractive index and thickness measured by single wavelength ellipsometer $(632.8 \mathrm{~nm})$ are not reliable without other independent measurements, extraction of $r$ from $K_{r}$ is not possible and therefore $r \sqrt{K_{r}}$ values are listed in Table 2 . However, monotonic increase in the $r \sqrt{K_{r}}$ values can be attributed to the densification in the film structure. The refractive index is expected to increase as a result of reducing the amount of suboxides with increasing substrate temperature $T_{\mathrm{S}}$ [23]. The increase with respect to $T_{\mathrm{s}}$ increment in the measured $r \sqrt{K_{\mathrm{r}}}$ values can be extracted from Fig. 5 for both oxide thicknesses. The dependence of $n$ on $T_{\mathrm{s}}$ at $633 \mathrm{~nm}$ wavelength for a constant laser power was presented in our earlier work [9], where it was confirmed that $n$ increases with respect to $T_{\mathrm{s}}$ increment and reaches similar values reported for as-fabricated $\mathrm{Ta}_{2} \mathrm{O}_{5}$ films obtained by other methods [4,7]. One can conclude that increasing substrate temperature, $T_{\mathrm{s}}$, results in formation of denser $\mathrm{Ta}_{2} \mathrm{O}_{5}$ oxide layers with higher refractive index $\left(n=\sqrt{K_{r}}\right)$ [9], with less number of defects in or at the interface of the grown films.

When $I-V$ curves are analyzed by applying PF formalism, we observe a general agreement in some part of the curves as seen in Fig. 5. It is clear from the experimental curves that more than one conduction mechanisms might be important for the current flow through these samples.

The presence of interfacial $\mathrm{SiO}_{2}$ layer affects the characteristics of the MOS devices. First of all, the overall effective dielectric constant of the insulating system is reduced. Second effect of the $\mathrm{SiO}_{2}$ layer would be an increase in the overall resistance of the grown layer. For a complete analysis, the interfacial $\mathrm{SiO}_{2}$ should be taken into account. Assuming that the accumulated charge at the $\mathrm{Ta}_{2} \mathrm{O}_{5} / \mathrm{SiO}_{2}$ interface is zero, the electric field distribution within the oxide layer $\left(\mathrm{Ta}_{2} \mathrm{O}_{5} / \mathrm{SiO}_{2}\right)$ is determined by

$\varepsilon_{\mathrm{T}} E_{\mathrm{T}}=\varepsilon_{\mathrm{S}} E_{\mathrm{S}}$

where $\varepsilon_{\mathrm{T}}, \varepsilon_{\mathrm{S}}$ are the permittivity of $\mathrm{Ta}_{2} \mathrm{O}_{5}$ and $\mathrm{SiO}_{2}$, and $E_{\mathrm{T}}$ and $E_{\mathrm{S}}$ are electric field across the $\mathrm{Ta}_{2} \mathrm{O}_{5}$ and $\mathrm{SiO}_{2}$ layers respectively. Then, applied voltage across the oxide layer $\left(\mathrm{Ta}_{2} \mathrm{O}_{5} / \mathrm{SiO}_{2}\right)$ can be given by the following expression:

$V=E_{\mathrm{T}} d_{\mathrm{T}}+E_{\mathrm{S}} d_{\mathrm{S}}$

where $d_{\mathrm{S}}$ and $d_{\mathrm{T}}$ are the oxide thicknesses of $\mathrm{SiO}_{2}$ and $\mathrm{Ta}_{2} \mathrm{O}_{5}$ layers. From the given equations, the electric field across the $\mathrm{SiO}_{2}$ and $\mathrm{Ta}_{2} \mathrm{O}_{5}$ can be obtained as;

$$
\begin{aligned}
& E_{\mathrm{S}}=\frac{V}{\frac{\varepsilon_{\mathrm{S}}}{\varepsilon_{\mathrm{T}}} d_{\mathrm{T}}+d_{\mathrm{S}}} \\
& E_{\mathrm{T}}=\frac{V}{\frac{\varepsilon_{\mathrm{T}}}{\varepsilon_{\mathrm{S}}} d_{\mathrm{S}}+d_{\mathrm{T}}} .
\end{aligned}
$$

Since the thickness of $\mathrm{SiO}_{2}$ is in the range of $2 \mathrm{~nm}$ and that of $\mathrm{Ta}_{2} \mathrm{O}_{5}$ is around $20 \mathrm{~nm}$, it is found that the $E$ field on $\mathrm{SiO}_{2}$ is much higher than on $\mathrm{Ta}_{2} \mathrm{O}_{5}$ Eqs. (5) and (6). On the other side, because of the difference in the bandgap of $\mathrm{Ta}_{2} \mathrm{O}_{5}(\sim 5 \mathrm{eV})$ and $\mathrm{SiO}_{2}(\sim 9 \mathrm{eV})$, charge 
carriers are accumulated at the $\mathrm{Ta}_{2} \mathrm{O}_{5} / \mathrm{SiO}_{2}$ interface and therefore the breakdown probability of $\mathrm{SiO}_{2}$ is high. When the top electrode is positively biased for a system of metal $/ \mathrm{Ta}_{2} \mathrm{O}_{5} / \mathrm{SiO}_{2} / \mathrm{p}$-Si, electrons are injected from the substrate into the $\mathrm{SiO}_{2}$ layer and tunnel through the impurity levels in the $\mathrm{Ta}_{2} \mathrm{O}_{5}$ or trapped at the $\mathrm{SiO}_{2} / \mathrm{Ta}_{2} \mathrm{O}_{5}$ interface. In the reverse bias situation, i.e. when the gate is negatively biased, electrons are injected from the metal gate. If the formation of $\mathrm{SiO}_{2}$ layer could be avoided, we might expect lower electric field across the insulator resulting in a reduced leakage current.

\section{Conclusions}

It has shown that $\mathrm{Ta}_{2} \mathrm{O}_{5}$ films with good quality can be grown by $\mathrm{Nd}$ :YAG laser oxidation $(\lambda=1064 \mathrm{~nm})$ at low temperatures. Best process conditions in terms of laser power and substrate temperatures were determined. The FTIR analyses and refractive index values $(\sim 1.9-$ 2.2) show that laser grown layers have good qualities being close to those of bulk $\mathrm{Ta}_{2} \mathrm{O}_{5}$. The oxide charges for the best oxides were found to be in the same range as those obtained by other technologies. The leakage current density, $J$, through the oxide decreased with the increment in the oxide thickness and the substrate temperature. The conduction mechanism is governed by the modified Poole-Frenkel mechanism in a wide region of the $I-V$ curve.

Even though promising results were obtained from Nd:YAG laser oxidation of Ta films on Si, the electrical properties and uniformity of the films can further be improved by optimizing the process conditions and post oxidation processes. The best conditions for $\mathrm{Nd}$ : YAG laser oxidation of Ta films are 300 and $350{ }^{\circ} \mathrm{C}$ for $T_{\mathrm{s}}$, and $3.3 \mathrm{~J} /$ $\mathrm{cm}^{2}$ pulse for laser beam energy density. In order to decrease the porosity, so do increase the refractive index of the films, post annealing procedure in vacuum can be applied to obtain denser layers.

Current mechanisms need to be studied in details with low temperature measurements and activation analysis as a forthcoming duty. Future work will focus on the given issues as well as more detailed structural analysis and interfacial properties of the grown film with respect to XPS depth profile analysis and additionally Transverse Electron Microscope cross sectional pictures.

\section{Acknowledgements}

This work has been supported by TUBITAK (Scientific and Technical Council of Turkey) under project number TBAG/U68. The authors would like to thank Prof. D. Sc. Elena Atanassova from Institute of Solid State Physics of Bulgarian Academy of Sciences for her excellent and valuable comments.

\section{References}

[1] S. Sayan, E. Garfunkel, S. Suzer, Appl. Phys. Lett. 80 (2002) 2135.

[2] Intern. Techn. Roadmap for Semiconduct. (ITRS) 2004 edition, http://public.itrs. net, last accessed date April 2008.

[3] L. Manchanda, M.D. Morris, M.L. Green, R.W. van Dover, F. Klemens, T.W. Sorsch, P.J. Silverman, G. Wilk, B. Busch, S. Aravamudhan, Microelectron. Eng. 59 (2001) 351.

[4] E. Atanassova, Microelectron. Reliab. 39 (1999) 1185.

[5] A.I. Kingon, J.P. Maria, S.K. Streiffer, Nature 406 (2000) 1032.

[6] G.D. Wilk, R.M. Wallace, J.M. Anthony, J. Appl. Phys. 89 (2001) 5243.

[7] C. Chaneliere, J.L. Autran, R.A.B. Devine, B. Balland, Mater. Sci. Eng. R22 (1998) 269

[8] G. Aygun, E. Atanassova, A. Alacakir, L. Ozyuzer, R. Turan, J. Phys. D: Appl. Phys. 37 (2004) 1569.

[9] E. Atanassova, G. Aygun, R. Turan, Tz. Babeva, J. Vac. Sci. Technol. A 24 (2006) 206.

[10] I.W. Boyd, J.Y. Zhang, Microelectron. Reliab. 40 (2000) 649.

[11] J.J. Yu, J.Y. Zhang, I.W. Boyd, Appl. Surf. Sci. 186 (2002) 57.

[12] J.Y. Zhang, Q. Fang, I.W. Boyd, Appl. Surf. Sci. 138-139 (1999) 320.

[13] E.H. Nicollian, J.R. Brews, MOS (Metal Oxide Semiconductor) Physics and Technology, John Wiley and Sons, New-York NY, 1982.

[14] H.P. Lin, J.G. Hwu, IEEE Trans. Electron Dev. 54 (2007) 3064.

[15] C. Chaneliere, J.L. Autran, R.A.B. Devine, J. Appl. Phys. 86 (1999) 480.

[16] P.M. Campbell, E.S. Snow, Mater. Sci. Eng. B 51 (1998) 173.

[17] S. Ezhilvalavan, T.Y. Tseng, J. Mater. Sci.: Mater. Electron. 10 (1999) 9.

[18] P.L. Young, J. Appl. Phys. 47 (1976) 235.

[19] P.L. Young, J. Appl. Phys. 47 (1976) 242.

[20] John G. Simmons, Phys. Rev. 155 (1967) 657.

[21] J.R. Yeargan, H.L. Taylor, J. Appl. Phys. 39 (1968) 5600.

[22] C. Chaneliere, S. Four, J.L. Autran, R.A.B. Devine, Microelectron. Reliab. 39 (1999) 261.

[23] G. Aygun, E. Atanassova, R. Turan, Tz. Babeva, Mater. Chem. Phys. 89 (2005) 316.

[24] G. Aygun, E. Atanassova, K. Kostov, R. Turan, J. Non-Cryst. Solids 352 (2006) 3134. 